\title{
Kernos
}

Revue internationale et pluridisciplinaire de religion grecque antique

4 | 1991

Varia

\section{Piété et impiété filiale en Grèce}

\section{Xavier De Schutter}

URL : http://journals.openedition.org/kernos/303

DOI : $10.4000 /$ kernos.303

ISSN : 2034-7871

\section{Éditeur}

Centre international d'étude de la religion grecque antique

\section{Édition imprimée}

Date de publication : 1 janvier 1991

Pagination : 219-243

ISSN : 0776-3824

Référence électronique

Xavier De Schutter, «Piété et impiété filiale en Grèce », Kernos [En ligne], 4| 1991, mis en ligne le 11 mars 2011, consulté le 30 avril 2019. URL : http://journals.openedition.org/kernos/303 ; DOI :

10.4000/kernos.303 
Kernos, 4 (1991), p. 219-243.

\title{
PIÉTÉ ET IMPIÉTÉ FILIALES EN GRÈCE
}

\author{
Quid est pietas nisi \\ voluntas grata in parentes? \\ CIC., Planc., 80
}

Le culte des morts est sans conteste la "pièce maîtresse" de la religion familiale, et le culte rendu par le fils à son père défunt en constitue l'élément principal. Or, cette dévotion filiale consiste d'abord en la reconnaissance de l'autorité paternelle et l'entretien du père dans ses vieux jours avant de s'exprimer par l'accomplissement des derniers devoirs et des rites commémoratifs adressés à son âme. En guise d'introduction au culte des morts, ces notes se proposent de mettre en lumière le fondement social, juridique et religieux sur lequel repose cette ferveur. Il m'a semblé que les rites accomplis par les descendants au nom de leurs géniteurs décédés gagnent à être replacés dans le contexte plus large des devoirs qu'impose la piété filiale à l'égard des parents vivants et des vieillards ${ }^{1}$.

\section{Universalité de la piété filiale}

Un rapide tour d'horizon nous rappellera que le respect des parents est une loi morale universelle et l'une des bases fondamentales de toute société comme de toute religion. On songe évidemment en premier lieu au commandement biblique "Honore ton père et ta mère" 2 . Même s'il n'existe pas dans le Coran d'équivalent du Décalogue, le thème a été

1 II est évident que la mort prématurée d'un fils renversera les rôles. Qu'on se souvienne de Priam implorant Achille de lui rendre la dépouille de son fils. Mais, même dans le cas «normal» où un père de famille décède, il resterait à préciser le rôle de la veuve ou de la fille : chez EURIPIDE (Hél., 1275), il est clairement dit que le devoir des funérailles revient à la mère, à la femme ou aux enfants, et l'histoire d'Antigone montre bien que le devoir de la sépulture s'applique autant entre frères et sœurs qu'entre enfants et parents.

2 Ex., XX, 12 (le Décalogue); XXI, 15-17 : «Et qui frappe/insulte son père ou sa mère sera mis à mort». Cette sanction, la peine capitale, prévue par le plus ancien recueil juridique paléotestamentaire, est plus sévère que celle prévue par le code babylonien d'Hammourabi, où l'enfant qui aura frappé son père aura les mains tranchées (\$ 195). Cf. aussi Lév., XIX, 3; Deut., XXVII, 16; Sir., III, 1-16. Pour le Nouveau Testament, cf. Ep. aux Eph., VI, 2-3; MT, XVI, 4-9; Mc, VII, 10. 
repris par les Sourates : «Nous avons commandé à l'homme le bien envers ses père et mère» ${ }^{3}$. Les mêmes prescriptions se retrouvent en Inde dans les lois de $\mathrm{Manou}^{4}$, et dans le Corpus de la tradition bouddhiste de Ceylan ${ }^{5}$. Plus que toute autre, les sociétés d'ExtrêmeOrient accordent une place prépondérante au culte des ancêtres familiaux et à la piété filiale : pour Confucius, la dévotion filiale (xiao) était l'un des préceptes majeurs de la morale qui doit guider l'action politique ${ }^{6}$, et le Japon moderne célèbre encore une fête annuelle adressée aux parents vivants ${ }^{7}$. Enfin, chez les peuples de culture archaïque, le respect pour la vieillesse répond souvent à une conception religieuse : les vieillards sont considérés comme les favoris des esprits et leur longévité comme une force mystique. Non seulement, ils sont dépositaires des traditions sacrées à transmettre aux jeunes générations, mais en outre ils constituent un véritable lien entre les vivants et les ancêtres ${ }^{8}$.

En Grèce aussi, le devoir de respecter ses parents, bien plus qu'une simple obligation morale, fut un précepte religieux aussi important que

$3 \quad$ II, 83; IV, 36; VI, 151; XVII, 23-24; XXIX, 8; XLVI, 15.

4 Les lois de Manou interdisaient au jeune homme qui avait abandonné sans raison son père, sa mère, ou son directeur spirituel, de prendre encore part à une cérémonie consacrée aux dieux ou aux ancêtres : III, 157; XI, 59; 62. Il était exclu du srâddha (repas funèbre) : III, 159. Celui qui maudissait ses parents était frappé d'une amende : VIII, 275.

5 W. RAHULA, L'enseignement du Bouddha d'après les textes les plus anciens, 1961, p. 149 (le Vasala-Sutta) : «Celui qui frappe ou blesse en paroles sa mère, son père, son frère, sa sœur ou ses beaux-parents, qu'il soit considéré comme un paria».

6 CoNFUCIUS, Entretiens, I, 2 : "Piété filiale et respect des aînés ne sont-ils pas la racine du ren ?» (Le ren, mansuétude et amour des hommes, est le Souverain Bien dans la pensée humaniste de Confucius). Cf. aussi I, 6; II, 5; 21; IV, 18; IX, $15 ;$ XIII, 20.

7 L. BerThER-CAILLET, Fêtes et rites des quatre saisons au Japon, 1981, p. 299.

8 L. LEVY-BRUHL, L'âme primitive, 1927, p. 268-274. Ceci ne doit pas nous faire oublier que certaines peuplades primitives ou antiques, poussées par une misère extrême, ont pratiqué à l'usage des vieillards la coutume du parricide légal ou du suicide obligatoire. Cf. S. DE BeAuvorr, La vieillesse, 1970, p. 72 sq.; G. GLOTZ, La solidarité de la famille dans le droit criminel en Grèce, 1904, p. 36 , n. 8 : l'auteur note que l'usage ne semble pas avoir existé en Grèce, mais selon STRABON, X, 5, 6, une loi de Céos prescrivait qu'une personne âgée de plus de soixante ans devait boire la ciguë afin de laisser la nourriture aux autres. Depuis l'enquête ethnographique d'HÉrodote, les Grecs connaissaient cette coutume «barbare" : I, 216; III, 38; III, 99. Cf. E. MEYER, Histoire de l'Antiquité (trad. franç.), t. I, 1912, p. 32-34. 
le respect des dieux et, dans la religion patriotique de l'Athènes classique, que l'amour de la patrie. Le sophiste Hippias d'Élis, qui en faisait une loi non-écrite, avait remarqué que le respect des parents se retrouve $\pi \alpha v \tau \alpha \chi 0 \hat{v}^{9}$, chez tous les hommes. La règle peut toutefois connaître des variantes : Hérodote avait été frappé durant son voyage en Égypte par le fait que les fils n'y étaient pas tenus de nourrir leurs parents âgés, mais que les filles ne pouvaient manquer à ce devoir ${ }^{10}$. Sophocle avait sans doute les Histoires d'Hérodote en mémoire lorsqu'il fit dire à Edipe que ses deux fils imitaient les coutumes égyptiennes en ne se souciant pas de son errance et en laissant ce soin à leurs sœurs Antigone et Ismène ${ }^{11}$. Par contre, Hérodote s'était laissé dire en Perse que personne n'y avait jamais tué son père ${ }^{12}$ : à prendre au pied de la lettre cette réflexion perse, plutôt présomptueuse, il n'y aurait jamais eu de mythe (on a envie d'écrire : de complexe) d'GEdipe au pays du Grand Roi. Quelque soixante ans plus tard, Xénophon nuança cette affirmation en relégant dans le passé cette légendaire vertu puisque, dans sa conclusion de la Cyropédie, il prétendit avoir montré que «les Perses sont aujourd'hui plus impies envers les dieux et plus sacrilèges envers les parents qu'autrefois» ${ }^{13}$. Plutarque rapporte la même assertion au sujet de Rome : aucun Romain ne se serait rendu coupable de parricide pendant six cents ans. "Le premier parricide connu, L. Hostius, est postérieur à la guerre contre Hannibal", précise-t-il ${ }^{14}$.

À l'injonction biblique "Maudit, celui qui méprise son père et sa mère" ${ }^{15}$, correspond chez Euripide cette parole de Thésée : "Malheur au fils qui n'est point, en esclave, soumis à ses parents» $16 . \Pi \alpha \tau \rho \grave{i}$ $\pi \varepsilon^{\prime} \theta \varepsilon \sigma \theta \alpha{ }^{17}$, telle est la dikè pour les enfants : «il n'y a pas de loi plus

9 XÉN., Mém., IV, 4, 20.

10 HDT., II, 35.

11 SopH., $E d$. Col, 337 sq.

12 HDT., I, 137.

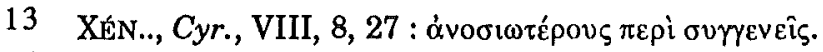

14 PluT., Rom., 22.

15 Deut., XXVII, 16. Cf. n. 2.

16 EUR., Suppl, 361-364; cf. aussi DIOG. LAËRCE, Thal., I, 37. L'Égypte connât une formule semblable : «le père est le maitre, le fils le serviteurs, cf. R.A. CAMINOS, Literary fragments in the hieratic script, 1956, 20 D, 1, 6.

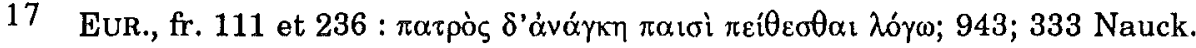
Cf. aussi APOLLOD., I, 8, 1, 1 : Toxeus mérite la mort pour avoir enfreint un

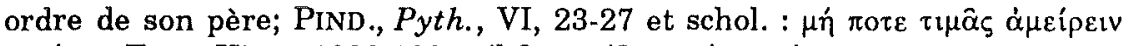

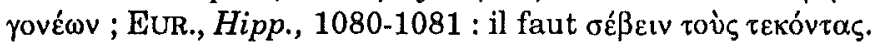


belle que d'obéir à un pèrem, lit-on chez Sophocle ${ }^{18}$. Honneur (ou crainte) des dieux, respect des parents et obéissance aux lois auraient pu être la devise de bon nombre de cités ${ }^{19}$. Même au sein de la République idéale de Platon, qui prône l'éclatement de la famille nucléaire au profit de la grande famille des concitoyens, les pères gardent toute leur autorité : pas plus que l'irrespect des dieux, celui des parents n'y sera toléré ${ }^{20}$. Mieux encore : chez Eschine, le mauvais traitement des parents est jugé comme une impiété car c'est manquer d'égard «envers ceux que nous devons honorer à l'égal des dieux» 21 . Les parents sont $i$ sothéoi, invectiver contre son père revient donc à blasphémer une divinité 22 .

\section{La pension alimentaire}

Que signifie exactement pour un Grec respecter ses parents? C'est bien sûr leur obéir, ne pas les insulter ni les frapper, c'est aussi les secourir en cas de danger et leur offrir un gite : abriter sous son toit un père, une mère, ou ses grands-parents affaiblis par la vieillesse, c'est avoir au foyer une statue que nulle autre ne surpasse en puissance pourvu qu'on lui rende le culte approprié23. Honorer ses parents implique aussi, dans le monde antique où la pension de retraite n'existait pas, leur subsistance dans leurs vieux jours. Il serait intéressant d'établir un dossier comparatif sur ce devoir que les Grecs appelaient géroboskia ou gérotrophia ${ }^{24}$. La Bible ne l'ignore pas : «Mon

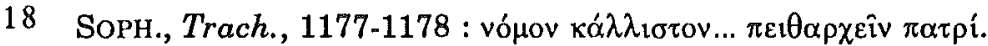

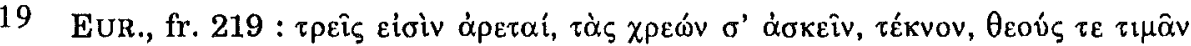

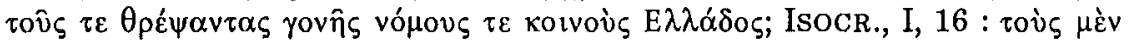

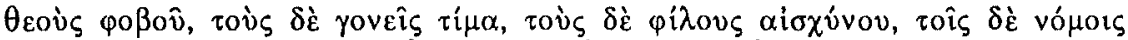

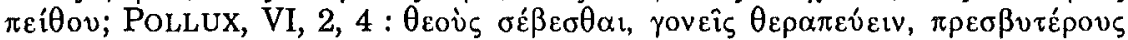

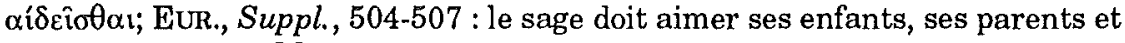
sa patrie; Platon, Ménon, 91a.

20 Platon, Rép., 386a; 443a; 615c; Lois, 930e. Dans le Criton, Platon affirme que si la violence est impie à l'égard d'un père ou d'une mère, elle l'est davantage envers la patrie (51c), et dans les Lois, il situe les offenses contre les parents après celles qui concernent les choses sacrées, les cultes privés et les tombeaux (885a).

21 Eschine, C. Tim., 28.

22 MEN., fr. 805-806 Nauck; DICÉOG., fr. 5 Nauck.

23 PLATON, Lois, 931a sq. : c'est un trésor qui échoit aux gens de bien lorsque leurs parents vieillissent auprès d'eux.

24 Le problème de la géroboskia reste actuel. Pour cet aspect de la gérontologie dans notre société, cf. S. DE BEAUVOIR, op. cit., p. 343 sq.; et J. TrISCHLER, Tu 
fils, prends soin de ton père dans sa vieillesse et ne l'afflige pas durant sa vie (...) C'est un blasphémateur, celui qui abandonne son père» ${ }^{25}$. Et Bouddha dit de même : «Celui qui, pouvant le faire, ne veut pas subvenir aux besoins de son père et de sa mère lorsqu'ils sont vieux, qu'il soit considéré comme paria» ${ }^{26}$. Seul le Christ se permet de transcender la morale commune au point de demander à ses disciples d'abandonner tout, y compris ses parents, pour le suivre et gagner le Royaume de Dieu : «qui aime son père ou sa mère plus que moi n'est pas digne de moi» 27 .

Aux yeux des Grecs, le comportement de certains animaux donnait l'exemple à suivre en matière d'amour filial. À un indésirable parricide qui se présente aux portes de Coucou-Ville-Les-Nuées, dont les lois promulguent qu'«il est beau de battre son père», il est rappelé que, selon les $\pi \varepsilon \lambda \alpha \rho \gamma \iota$ коi vó ${ }^{\circ}$, «lorsque le père cigogne a mis tous les cigogneaux en état de voler en les nourrissant, les petits doivent à leur tour nourrir leur père» ${ }^{28}$. Ces lois des cigognes ${ }^{29}$ sont respectées par d'autres animaux encore : l'alcyon, par exemple, prend en charge son père que la vieillesse a rendu incapable de voler et de se nourrir : «il le porte et le nourrit" ( naturelle, mais, remarque Xénophon, l'homme est encore «le plus disposé d'entre tous les animaux à rendre à ses parents vivants ou morts les soins qu'il en a reçus» ${ }^{31}$.

Cette notion de piété filiale a donné lieu à certaines histoires touchantes ${ }^{32}$. L'une d'elles raconte que deux jeunes gens de Catane portèrent sur leur dos leurs parents afin de les sauver d'un flot de lave;

honoreras la personne du vieillard. Réflexions éthiques sur quelques problèmes relatifs aux personnes âgées, 1987.

25 Sir., III, 12-16.

26 W. RAHUla, op. cit., p. 149. Pour la Chine, cf. Confucius, op. cit., II, 7-8.

27 MT, X, 37; Lc, XIV, 26-27 et XVIII, 29.

28 ARIsTOPH., Ois., 753 sq.; 1347 sq.

29 Sur les $\pi \varepsilon \lambda \alpha \rho \gamma$ ikò vó $\mu$ ò, cf. Soph., El., 1058; Platon, Alc. I, 135e; Souda et

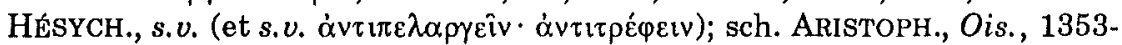
1359.

30 PLUT., Mor., 983b; ARISTote, Hist. anim., IX, 13 (les cigognes et les guêpiers); ÉLIEN, Nat, anim., IX, 1 (les lions qui n'ont pas reçu cette loi de Solon, mais de la nature).

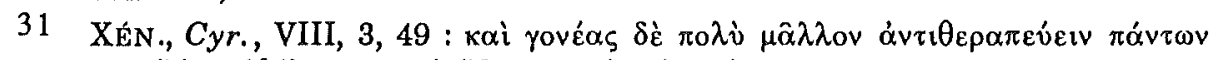

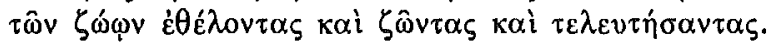

32 Celle de Cléobis et Biton par exemple (HDT., I, 31) illustre notre thème. C'est comme «modèles d'amour fraternel et filial» que PluTARQue les présente (Sol., 27). 
cette charge retardait évidemment leur course et la lave les rattrapa, mais même en danger de mort, ils ne voulurent pas abandonner leurs parents, et la lave se scinda en deux coulées qui les dépassèrent sans les

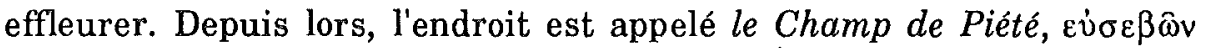
$\chi \hat{\omega} \rho_{0 v}{ }^{33}$. Le parallèle avec l'histoire du pieux Énée sauvant Anchise des flammes est évident : à Rome, le terme pietas désigne "au sens technique exclusivement la disposition pieuse et zélée qui se donne cours dans les rapports réciproques des parents et des enfants» 34 . Xénophon déjà avait présenté Énée comme le champion de l'eusebeia,

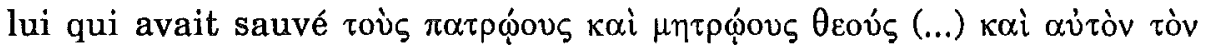

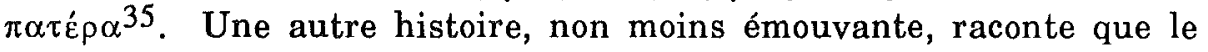
prince Tectaphos avait été condamné à mourir de faim dans un souterrain, mais sa fille Éérié, qui venait d'être mère, obtint la permission de lui rendre visite et elle put ainsi le sauver en lui donnant le lait de son sein ${ }^{36}$.

Dans l'Athènes classique, rien n'était laissé au hasard : lorsqu'un citoyen mourait en héros à la guerre, laissant derrière lui une famille endeuillée, l'État manifestait sa reconnaissance en lui accordant de grandioses funérailles publiques au Céramique et en prenant en charge les orphelins, la veuve et les parents privés de soin. Platon a évoqué dans son oraison funèbre les lois «pour les enfants et les parents des morts tombés à la guerre»; il nous apprend que l'archonte polémarque était chargé "de protéger contre l'injustice les pères et les mères de ces morts». En résumé, la cité jouait dans ce cas «à l'égard des morts, le rôle de l'héritier et du fils : à l'égard du fils, celui du père, et à l'égard

33 LyC., C. Léocr., 95-97. Quant à ceux qui avaient abandonné leurs parents, ils périrent tous. LYCURGUE mentionne ce récit pour mieux illustrer l'impiété de Léocrate kqui a livré ses parents à l'ennemi et privé les morts des honneurs qui leur sont dus». Cf. aussi PAUS., X, 28, 4. Ces deux jeunes gens avaient leur statue à Catane et étaient représentés parmi d'autres exemples de piété filiale sur les reliefs des bases des colonnes du temple d'Apollon à Cyzique, cf. A. REINACH, Recueil Milliet. Textes grecs et latins relatifs à l'histoire de la peinture ancienne, 1921, p. 111, n. 3.

34 G. WISsowa, Religion und Kultus des Römer, $1971^{2}$, p. 331.

35 XÉN., Cyr., I, 15.

36 NonNos, Dion., XXVI, 101-102. Selon une légende romaine, le temple de la déesse Pietas à Rome a été construit à l'endroit où une fille aurait nourri de son propre sein sa mère qui dépérissait en prison, cf. PLINE, Hist. nat., VII, 121; VAL. MAX, V, 4, 7; dans FESTUS, 209, c'est le père qui a été nourri par la fille. II n'est pas impossible que l'origine de la légende soit grecque, cf. VAL. MaX., V, 4; HYGIN, Fab., 254. 
des parents, celui du tuteur» ${ }^{37}$. Mais la générosité de l'État athénien s'arrêtait là : seuls les parents des héros bénéficiaient de cette caisse de pension. C'est pourquoi une épigramme funéraire tardive nous montre deux fils se lamentant non pas sur leur mort prématurée, mais sur le sort de leur père dont la vieillesse est laissée dans un pénible abandon ${ }^{38}$.

L'assistance à la vieillesse était d'ailleurs l'un des buts de la procréation. Hésiode conseillait d'affronter les soucis du mariage et la race maudite des femmes plutôt que de rester célibataire, car un fils est

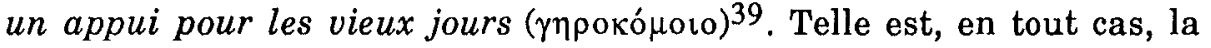
théorie, mais souvent la réalité évoque davantage la décadence des mœurs annoncée par Hésiode. Un jour, la race de fer à laquelle appartient le poète sera entièrement dominée par l'hybris, et, entre autres indices de cette déchéance, les hommes ne montreront que mépris à l'égard de leurs vieux parents : ils refuseront les aliments aux vieillards qui les ont nourris, et Zeus n'aura plus qu'à anéantir cette humanité irrespectueuse ${ }^{40}$. Aux prophéties d'Hésiode font écho les craintes des Euménides qui prévoient un temps où les parricides ne seront plus châtiés ${ }^{41}$. Il y a lieu, on le devine déjà, de nuancer l'affirmation suivante de G. Glotz : "les Grecs se sont toujours distingués des autres Aryens par l'amour filial et le respect de la vieillesse» ${ }^{42}$. Le refus d'accomplir le devoir de la géroboskia et le manque d'amour filial ont en effet été un thème majeur de la littérature de l'époque classique. Qu'il s'appelle Edipe ou Phidippide, le person-

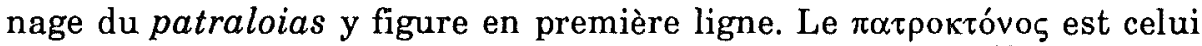
qui tue son père; le $\pi \alpha \tau \rho \alpha \lambda_{o} \alpha_{\alpha \varsigma}$ est plutôt celui qui le frappe $e^{43}$. Il est vrai

37 Platon, Ménex., 248e-249c; Lys., II, 75; Thuc., II, 46.

38 Anth. Pal., VII, 540.

39 HÉs., Théog., 603-607. Cf. aussi infra, n. 56.

40 HÉs., Trav., 185-188. Dès l'époque homérique, la coutume imposait l'entretien des parents, cf. $l l$., IV, 477 : Ajax dompte de sa lance deux Troyens qui ne

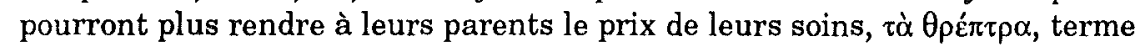
qui correspond à $\theta \rho \varepsilon \pi t i ́ p ı$ chez Hésiode.

41 EsCH., Eum., 490 sq.

42 G. GLOTZ, op. cit., p. 37, n. 1.

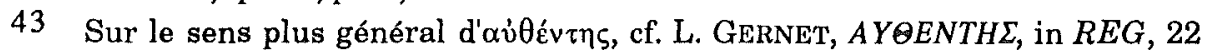
(1909), p. 13-32 (repris in Droit et société dans la Grèce antique, 1955, p. 29 50). Selon GERNET, le terme désignait originellement celui «qui tue un de ses parents» avant de désigner le umeurtrier en général, celui «qui tue de sa propre main». Le mot latin parricida aurait connu la même évolution sémantique, cf. L. GeRNET, Parricidas, in Rev. Phil. Litt. et Hist. anc., 11 (1937), 
que Cronos avait montré l'exemple en châtrant son père Ouranos et que Zeus lui-même avait détrôné son père.

\section{Le thème du Patraloias}

Dans les dernières décennies du Ve siècle et au début du IVe siècle, Aristophane a plusieurs fois porté le sujet sur la scène du théâtre. J'ai déjà fait allusion à sa pièce Les Oiseaux; dans Les Nuées, il prit plaisir à imaginer une nouvelle constitution qui délivrerait enfin les fils de leurs devoirs contraignants à l'égard des parents et les autoriserait à battre leur père (v. 1420-1424). Enfin, dans sa République imaginaire dirigée par l'Assemblée des femmes, il suppose que si les enfants considèrent tous les anciens comme leurs pères, ils les étrangleront tous, puisqu'aujourd'hui déjà ils étranglent leur vrai père (636-640). Il n'y a donc plus de justice ni de moralité : aux termes de la loi, il ne sera

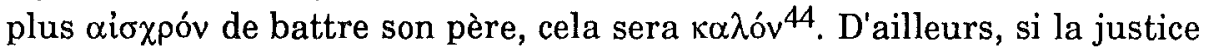
existait réellement, Zeus lui-même aurait péri pour avoir enchaîné son père ${ }^{45}$. Socrate, quant à lui, ne croit pas à ces vieilles légendes immorales qui prêtent de tels comportements aux dieux : ce ne sont que des balivernes ${ }^{46}$, et Platon les frappe de la censure car elles donnent le mauvais exemple aux enfants ${ }^{47}$. Les propos d'Aristophane font écho à l'enseignement des sophistes et s'inscrivent dans une crise générale des valeurs traditionnelles au cours de la guerre du Péloponnèse $e^{48}$. Ultérieurement, Démosthène renverra à cette tradition en affirmant que le secours aux parents est imposé "par la nature et par la loin"49, mais, à la fin du Ve siècle, c'est par opposition aux lois humaines que les sophistes proclamaient «naturel» de ne pas respecter les vieux ${ }^{50}$.

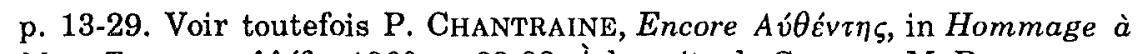

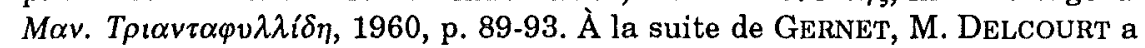
montré que le suicide et le parricide sont deux thèmes liés, cf. M. DELCoURT, Le suicide par vengeance dans la Grèce ancienne, in $R H R, 119$ (1939), p. 154171. Ajax, par exemple, avant de se suicider, maudit ses persécuteurs et leur souhaite d'être tués par leurs propres enfants, cf. SopH., Ajax, $835 \mathrm{sq}$.

44 ARISTOPH., Ois., 753-759.

45 ARIstoph., Nuées, 904-906; Eur., Hér. fur., 1317; EsCH., Eum., 640.

46 Platon, Euth., 5e-6a.

47 Platon, Rép., 378b.

48 E. LEVy, Athènes devant la défaite de 404. Histoire d'une crise idéologique, 1976 (Bibl. des Ec. fr. d'Athènes et de Rome, 225), p. 83 sq., en part. p. 92 et 104.

49 Dem., Ne Phil., 40.

50 P. Roussel, La critique de l'autorité paternelle aux IVe et Ve siècles, in MAI, 43, 2 (1951), p. 215-227, en part. p. 216-217 : «la critique de la loi ou de la 
Il semble bien qu'à l'époque classique plus d'un père ait dû redouter la fourberie de son fils : "malheur à celui qui remet le pouvoir à son rejeton avant de mourir", dit Euripide, "car il finira sa vie sous la domination de ses enfants» 51 . Faute de véritables griefs qu'on eût pu lui imputer, Socrate lui-même (le professeur de Phidippide !) fut contraint à boire la ciguë pour avoir appris à la jeunesse à bafouer les pères ${ }^{52}$. On se souviendra aussi du débat soulevé par Platon dans l'Euthyphron sur les limites de la déférence à l'égard des parents : y a-t-il impiété à porter une accusation contre son père lorsque celui-ci est entaché de la souillure d'un meurtre ${ }^{53}$ ? Par ailleurs, faisant l'apologie des institutions lacédémoniennes, où la gérousia archaïque entretenait les privilèges des kaloi kagathoi, Xénophon déplore que les Athéniens ne respectent pas la vieillesse, "eux qui, en commençant par leurs pères, dédaignaient les vieillards» ${ }^{54}$. Il va sans dire que la gérontocratie spartiate implique le respect du père, mais à Athènes - et ici le débat devient politique - les luttes entre partis ont quelquefois opposé pères et fils, ce qui contribuait évidemment à l'affaiblissement des liens de parenté 55 . Chez Platon aussi, le problème se pose en termes

coutume et le recours à la loi naturelle ont été d'usage courant dans la sophistique». Cet article, qui traite de notre sujet, n'en aborde que l'aspect philosophique et développe les débats sophistiques auxquels font allusion les opinions de SOCRATE et ARISTOTE. Cf. aussi P. ROUSSEL, La famille athénienne, in $B A G B$, Suppl. Lettres d'Hum., 9 (1950), p. 36-42. Sur le rôle attribué à ANTIPHON le sophiste dans la critique de l'autorité paternelle, cf. S. LURIA, Väter und Söhne in den neuen literarischen Papyri, in Aegyptus, 7 (1926), p. 243-268. Le fr. I, 4, dit que «ceux qui sont bienfaisants envers leurs parents, même quand ces parents agissent mal à leur égard" obéissent contre leur intérêt à la loi plutôt qu'à la nature. LuRIA a toutefois exagéré limportance de l'influence d'ANTIPHON sur les jeunes générations, cf. E. DoDDS, Les Grecs et l'irrationnel, 1977, p. 68, n. 106; E. LEVY, op. cit., p. 104, n. 4.

51 Eur., fr. 803 Nauck.

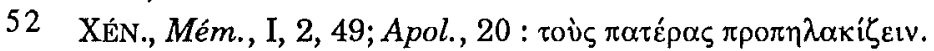

53 Cf. aussi ARISTOTE, Eth. Nic., 9, 2. Roussel, art. cit., p. 226-227 : l'auteur note que, si ces problèmes faisaient scandale à la fin du Ve et au début du IVe siècle, avec ARISTOTE par contre la question avait perdu de son acuité et était traitée sans passion car l'autorité parternelle avait alors perdu de son poids.

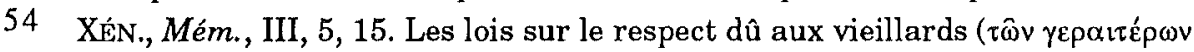
$\tau \grave{\alpha}$ vó $\mu \uparrow \alpha$ ) auxquelles fait allusion AnTIPHON, Trois tétr., I, 6, nous reste inconnues. Comme le remarque L. Gernet (dans son éd. dans la Coll. Univ. France, 1923, p. 89, n. 1), il s'agit sans doute d'un lieu commun moral plutôt que juridique.

55. Thuc., III, 82, 6. Cf. aussi VI, 12-13 : en réponse au discours de Nicias qui conseille aux hommes mûrs de ne pas suivre le jeune Alcibiade dans son 
d'institutions politiques : comme les réformes farfelues d'Aristophane, ses projets idéalistes expriment les préoccupations de l'époque. En imaginant sa République, dans laquelle les citoyens devront «témoigner à leurs pères le respect, le soin et la soumission que commande la loi paternelle envers les parents (463e-d)», le philosophe rêvait de voir disparaitre les deux régimes pervertis que sont la démocratie et la tyrannie. Dans le premier, en effet, «le fils s'égale à son père et n'a ni respect ni crainte pour ses parents» (562e), dans le second, le tyran qui tire ses ressources du peuple est comme le fils qui se fait entretenir par son père, alors que c'est le père qui doit être nourri par le fils. Le tyran est donc un patraloias et un "mauvais nourricier de ses

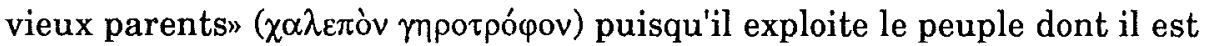
issu (568e; 569b). Il dépouille ses parents «du patrimoine» $(\tau \hat{\omega} v$ $\pi \alpha \tau \rho \varphi \omega \omega, ~ 547 a)$, oubliant la leçon d'Hésiode selon qui le fils est censé

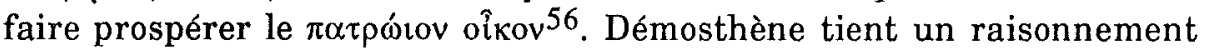
analogue lorsqu'il dit que puisque «tous les citoyens sont les pères communs de la cité entière», celle-ci doit pourvoir à leur entretien ${ }^{57}$.

On perçoit donc des tensions entre générations et un malaise au sein de la société athénienne qui a cherché, et réussi, à se dégager de sa structure familiale archaïque fondée sur l'autorité absolue du pater. familias. Le père, chef de famille et chef du culte domestique, a été le pivot autour duquel s'articulait la société archaïque dont l'organisation patriarcale était héritée du passé indo-européen ${ }^{58}$. Même si la Grèce historique n'a pas connu le régime rigoureux de la patria potestas romaine, le chef de famille y était originellement l'oikoio anax, et son autorité est restée très grande jusqu'à l'époque classique. Aussi,

expédition téméraire, celui-ci répond (VI, 28,6) en exhortant les Athéniens à concilier les efforts de la jeunesse et de la vieillesse.

56 HÉs., Trav., 376-378. Cf. XÉN., Econ., VII, 18-19 : XÉNOPHON s'en souvint lorsqu'il écrivit que le mariage permet aux humains «de s'assurer des soutiens pour nourrir leur vieillesse» ( d'IsÉE sont fort précieux à ce sujet : ils nous montrent qu'une préoccupation

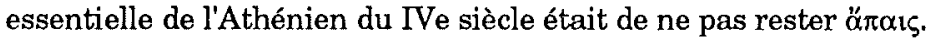

57 DÉm., IVe Phil., 41.

58 É. BENVENISTE, Le vocabulaire des institutions indo-européennes, I, 1969, p. 205 sq. : «la structure familiale qui se dessine à travers le vocabulaire est celle d'une société patriarcale reposant sur la filiation paternelle (...); d'autre part, les termes de parenté se rapportent à l'homme; ceux qui intéressent la femme sont peu nombreux, incertains et de forme souvent flottante». Cf. ARISTOTE, Pol., I, 2, 6-7; I, 5, 2; I, 12, 3 : à l'origine, toute famille était soumise à la royauté du plus âgé. Cf. les remarques de RousseL, art. cit., p. 215 sq.; 224 225; et Platon, Lois, 701b. 
respecter ses parents, c'est avant tout respecter son père. Aristophane a beau dire qu'il est pire de battre sa mère que son père ${ }^{59}$, c'est surtout ce dernier que les lois divines protègent. L'idéologie patriarcale se justifiait d'ailleurs par la prétention hypocrite que l'on peut devenir père sans l'intervention d'une femme. Voilà pourquoi «il n'y a pas un homme pour se proclamer le fils de sa mère, on est le fils de son père !n 60

\section{La kakôsis goneôn. Sanctions prévues par le droit}

Les allusions d'Hésiode prouvent que les tensions familiales n'ont pas épargné la Grèce du VIIe siècle. En tout cas, elles étaient suffisamment vives au VIe siècle pour que Solon ait ressenti le besoin de légiférer sévèrement sur les droits des parents et les devoirs des enfants. Manifestement, la docilité des enfants n'allait pas de soi. Quoique Vitruve ait remarqué que «dans toutes les cités grecques», les lois obligeaient les enfants à obéir à leurs parents ${ }^{61}$, nous ne connaissons en détail que la législation d'Athènes et devons nous contenter de deux inscriptions lacunaires pour Mycènes et Delphes. À Mycènes, une inscription du Ve siècle mentionne des juges chargés de rendre justice aux parents «en conformité avec les textes» ${ }^{62}$. Pour Delphes, nos renseignements sont un peu plus précis grâce à une stèle qui se dressait dans le sanctuaire d'Apollon : au dernier tiers du IVe siècle ou au début du IIIe siècle, la cité décida de faire graver une loi $\pi \varepsilon \rho i$ $\tau \hat{\omega} v$ yové $\omega v^{63}$. Aux termes de cette loi, "si quelqu'un refuse de nourrir son père ou sa mère, le Conseil fera enchaîner le coupable et le jettera en

59 ARISTOPH., Nuées, 1444 sq. Cf. XÉN., Mém., II, 2, où Socrate enseigne à son fils que l'humeur acariâtre de sa mère ne doit pas l'empêcher de la vénérer. C'est à sa prétendue faiblesse que la femme doit sa respectabilité. ARISTOTE s'en étonnait : si le sexe féminin est inférieur au masculin, pourquoi est-il plus criminel de tuer une femme qu'un homme ? Cf. ARISTOTe, Probl., 29. Les droits de la mère ont toujours été discutés, cf. SÉNĖQUE LE RHÉTEUR, Controv., VII, 4.

60 Eur., fr. 1048 Nauck; Or, 552-554. Cf. EsCH., Eum., 658-666 : «ce n'est pas la mère qui engendre, celui qui engendre, c'est le mâle".

61 VITR., VI, 3.

62 Inscriptiones graecae ad inlustrandas dialectos selectae, 4e éd. F. SOLMSEN-E. FraENKEL, 1966, n 29; U. vON WILAMOWITZ-MoEllendorF, Aristoteles und Athens, II, 1893, p. 48, n. 26.

63 L. LERAT, Une loi de Delphes sur les devoirs des enfants envers leurs parents, in $R P h, 17$ (1943), p. 62-86 : selon LERAT, la loi existait déjà auparavant et la cité décida de la sortir des archives «probablement parce que les Delphiens avaient tendance à la perdre de vue», p. 70. 
prison» ${ }^{64}$. Pour Delphes toujours, L. Lerat a relevé que les actes d'affranchissement du IIe siècle av. J.-C. trahissent le souci de la part des maîtres de trouver en la personne de leurs esclaves des soutiens pour leurs vieux jours : "l'affranchi remplace véritablement l'enfant que le maître n'a pas eu ou qu'il a perdun ${ }^{65}$, car la libération n'était accordée qu'à la condition de recevoir en retour nourriture, soins et devoirs funéraires.

Tournons-nous à présent vers le droit attique : à Athènes,

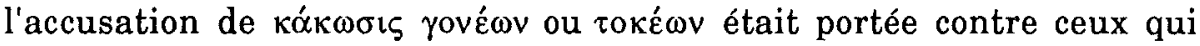
avaient outragé d'une façon ou d'une autre un ascendant, qui lui avaient refusé l'assistance ou la nourriture, ou enfin qui ne lui avaient pas rendu les derniers devoirs. La loi s'appliquait également aux fils adoptifs ${ }^{66}$, ce qui nous rappelle que la cause de l'adoption était bien souvent identique à celle des affranchissements dont il vient d'être question. L'action était introduite et instruite par l'archonte éponyme ${ }^{67}$, et la peine consistait en l'atimie partielle qui entraînait la perte des droits civiques ${ }^{68}$. Cette loi était attribuée à Solon ${ }^{69}$, mais le législateur s'est sans doute borné à codifier et à préciser les anciennes coutumes patriarcales en la matière : limitant les droits du père, il dispensa du devoir de géroboskia les enfants qui n'avaient pas reçu de leurs parents le minimum d'instruction nécessaire pour gagner leur vie, ainsi que les enfants nés d'une courtisane (les nothoi) ${ }^{70}$. De plus, le père qui avait livré son enfant à la prostitution perdait le droit d'être nourri et logé par son fils devenu adulte, mais cette conduite abjecte ne suffisait toutefois pas à libérer le fils du devoir de la sépulture ${ }^{71}$. Solon précisa encore que le citoyen condamné pour kakôsis goneôn qui oserait pénétrer sur

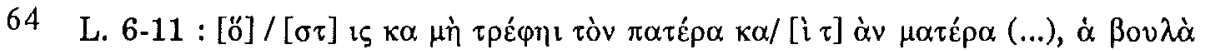

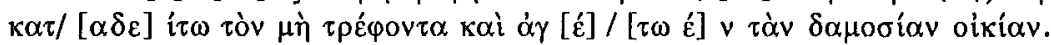

65 LERAT, art. cit., p. 82.

66 ISEE, III, 46 : une héritière maltraitée par son fils adoptif qui l'a dépouillée de la

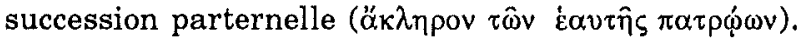

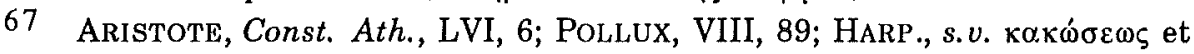

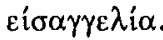

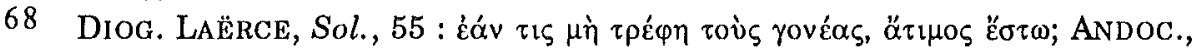
Sur les myst., 74.

69 PluT., Sol., 22; ÉLIEN, Nat. des anim., IX, 1; et n. 68, 70, 72.

70 PLUT., Sol., 22.

71 Eschine, C. Tim., 13-14. Confucius aussi prescrivait au fils de respecter ses parents même s'il était maltraité par eux, cf. Entretiens, IV, 18. 
l'agora serait passible d'emprisonnement ${ }^{72}$. Les ascendants que la loi

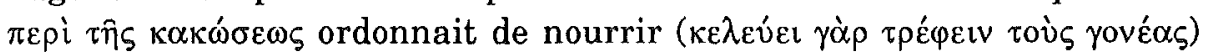
étaient "le père, le grand-père et la grand-mère, le bisaïeul et la bisaïeule, s'ils vivent encore" : ce devoir s'applique donc aux ascendants de trois générations, ceux dont on hérite des biens, mais on ne peut y manquer "même s'ils n'ont aucune fortune à laisser" ${ }^{73}$.

Dans sa législation fictive, Platon a accordé de longs développements au problème de l'impiété filiale. Il vaut la peine de s'y arrêter. Pour le parricide, tout d'abord, son verdict est la peine de mort (Lois, 869a-b; 854e-855a). Son cadavre devra ensuite être jeté hors de la cité, à un carrefour (c'est-à-dire abandonné à l'infernale Hécate qui règne la nuit dans les carrefours). Les magistrats lapideront sa dépouille pour purifier symboliquement la cité et l'abandonneront nu, sans sépulture, ö $\tau \alpha \varphi$ ov (873a-b; 878e $)^{74}$. Après le patroktonos, Platon examine le cas du patraloias qui aura osé "porter la main sur un père, une mère ou des aïeux et user envers eux de violence et de mauvais traitements» sans craindre les dieux Vengeurs : en attendant les tourments pires que la mort elle-même qui lui seront infligés dans l'Hadès (880e-881b), il sera banni à perpétuité de la cité et se verra interdire tous les temples. S'il rentre au pays malgré tout, il sera puni de mort ${ }^{75}$. Quiconque aura le moindre rapport avec lui contractera une souillure (881d-e). Le législateur pousse le souci jusqu'à prévoir dans les détails les plus menus le sort qu'il conviendra de réserver à ceux qui auraient été témoins d'un acte sacrilège envers des parents sans intervenir (881b-d, et infra, n. 122) ${ }^{76}$. Quant à celui qui ne soignera pas convenablement ses parents et ne sera pas attentif à leurs désirs, il sera puni «du fouet et de

72 DÉm., C. Timocr., 103-105 : en pareil cas, le coupable est mis en prison par les Onze, et l'Héliée fixe la peine afflictive ou pécuniaire; il reste en prison jusqu'à acquittement complet de l'amende.

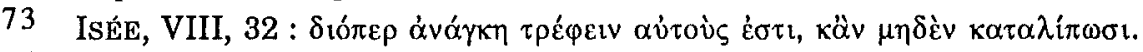

74 Chez SoPHOCLE déjà, le parricide n'a pas droit à être enseveli dans sa patrie thébaine, cf. $E d$. Col., 406-407. Cf. aussi le sort de Polynice, infra, n. 126.

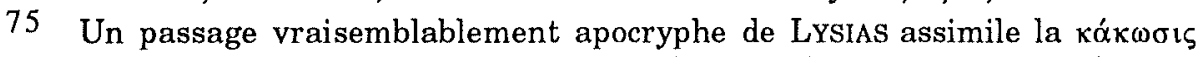

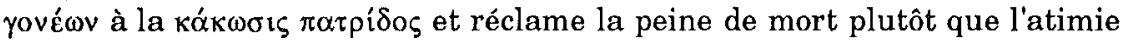
prévue par les lois athéniennes, cf. LYS., C. Agor., 91.

76 Une telle accusation ne se faisait évidemment pas à la légère : un citoyen à qui l'on avait injustement reproché d'avoir tué son père pouvait intenter une $\delta$ íkn

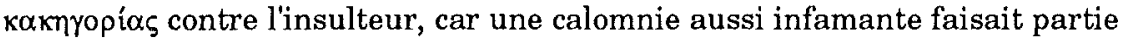
du catalogue légal des $\dot{\pi} \pi \rho \rho p \dot{\tau} \tau \alpha$, cf. LYs., X, 1-2; $6 ; 8 ; 21-22$. 
la prison" si c'est un fils de moins de quarante ans, tandis que les coupables plus âgés seront jugés par un tribunal (932b-c) ${ }^{77}$.

L'impression qui se dégage de l'ensemble de ces prescriptions de Platon est, outre la minutie, une sévérité qui évoque davantage les anciennes lois draconiennes que la législation classique d'inspiration solonienne.

\section{Sanctions prévues par les phratries athéniennes}

La perte des droits civiques qu'entraînait une kakôséôs graphé se vérifie également dans la docimasie des archontes. En effet, lorsque les bouleutes procédaient à la docimasie, sorte de vérification du certificat de bonne vie et mours du citoyen athénien, pour s'assurer que le candidat à l'archontat répondait aux conditions d'accès à cette magistrature, ils se renseignaient sur sa conduite envers ses parents : $\varepsilon \dot{i}$

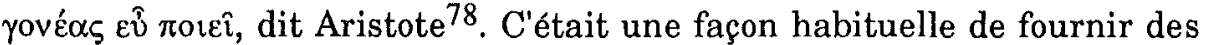
présomptions de moralité que de pouvoir affirmer : «je n'ai jamais élevé la voix contre mon père» ${ }^{79}$. Xénophon en fournit l'explication morale et religieuse : "si un homme ne prend pas soin de ses parents»

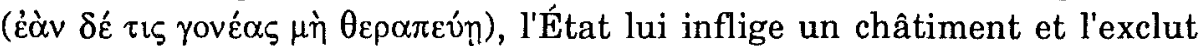
des magistratures ( $\dot{\alpha} \pi \circ \delta$ oк $\mu \alpha \dot{\alpha} \zeta o v \sigma \alpha)$ parce qu'un homme aussi indigne ne saurait rien faire de beau ni de juste, et les sacrifices publics qu'il offrirait déplairaient aux dieux ${ }^{80}$. De même, le patraloias et le fils négligent perdront le droit de prendre la parole devant l'Assemblée du peuple ${ }^{81}$.

77 Platon n'expose pas ici des idées entièrement personnelles, quoi qu'en dise G. GLOTz (dans son exposé sur la kakôséôs graphè, in C. DAREMBERG-E. Saglio, Dictionnaire des Antiquités, s.v.) puisque la loi de Solon ordonnait d'emprisonner le coupable rebelle qui, après condamnation, osait encore pénétrer sur l'agora, et que celle de Delphes condamnait le fils impie à être enchaîné et jeté en prison. On retrouve la même procédure à Rome : $Q u i$ parentes non aluerit, uinciatur, cf. QUINT., Inst. or., V, 10, 97; VII, 1, 55 et 6, 5. L'obligation alimentaire ne semble pas avoir été édictée par la loi romaine avant l'époque des Antonins, cf. Dig., XXV, 3, 5; XXXIV, 1, 3; Cod. Just., V, 25, 1-3. Pour plus de détails, cf. les notes de J. Cousin dans son éd. de Quintilien, op. cit., t. III, 1976, p. 240, et t. IV, 1977, p. 216 (Coll. Univ. France).

ARISTOTE, Const. Ath. LV, 2-3; 45, 3; Pollux, VIII, 44-45; 85-86.

79 LYS., XIX, 59.

80 XÉn., Mém., II, 2, 13. Dans Din., C. Aristog., 17, c'est ce que mérite Aristogiton pour avoir maltraité son père.

81 Eschine, C. Tim., 28. La même défense sera faite à ceux qui ont dilapidé les

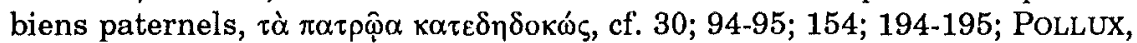
VII, 44-45. 
Le futur archonte devait également être dûment inscrit sur le registre des phratères, ce dont s'enquéraient les bouleutes en lui demandant s'il participait au culte d'Apollon Patrôos ${ }^{82}$. Or, dans un passage des Euménides d'Eschyle, où le choryphée accuse Oreste d'avoir répandu le sang de sa mère, il est dit qu'après un tel crime, Oreste ne sera plus admis aux lustrations des phratries ${ }^{83}$. Cette allusion prouve que le citoyen parricide, plus exactement matricide dans le cas d'Oreste (le texte dit $\mu \eta \tau \rho \hat{\varphi}$ ov $\delta \dot{\mu} \mu \alpha \varsigma$ et $\alpha \hat{i} \mu \alpha \mu \eta \tau \rho \hat{\varphi}$ ov, v. $84 ; 261)^{84}$, était exclu du rang des phratères qui sacrifiaient sur leurs $\beta \omega \mu$ oi $\pi \alpha \tau \rho \hat{\varphi} \mathrm{Q}^{85}$. Comme les exilés, il était banni des sacrifices offerts aux $\theta \varepsilon \circ i$ $\pi \alpha \tau \rho \hat{\omega} \iota^{86}$. Concrètement, cela signifie que son nom était rayé du

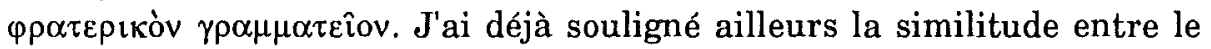
serment que prêtait le père devant ses compagnons de phratrie lorsqu'il leur présentait son fils légitime à l'occasion de la cérémonie couréôtis et celui que prêtait le candidat à l'archontat lors de la docimasie ${ }^{87}$. Ici encore, on voit bien que les deux procédures étaient parallèles : le fils

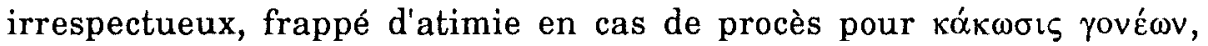
était invalidé lors de son examen devant les bouleutes et perdait son titre de phratère. En temps normal, "le commencement de la vie" était

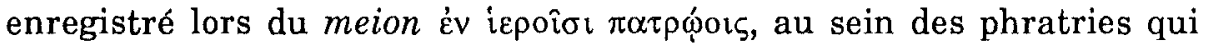
tenaient à jour le registre des citoyens de plein droit. Cette inscription était confirmée à l'adolescence lors de couréôtis, et les noms n'étaient effacés qu'à la mort, s'il faut en croire les Lois de Platon (785a), mais le fils impie était condamné à une mort sociale dès avant son décès.

\section{Sanctions prévues par la religion}

Tout porte à croire que la personne du paterfamilias avait été placée sous la protection des dieux avant même que les peines prévues par le droit n'aient été codifiées. En d'autres termes, le devoir civil du respect du père a d'abord été un devoir religieux qui semble universellement lié à la figure archétypale du père.

82 X. De Schutter, Le culte d'Apollon Patrôos à Athènes, in AC, 56 (1987), p. $118 \mathrm{sq}$.

83 Esch., Eum., 653-656.

84 Quant à Edipe, c'est le $\pi \alpha \tau \rho \hat{o ̣ ̂} \alpha$ î̉ $\alpha$ qu'il a versé avant de s'unir à sa mère, cf. SopH., $E d$. Roi, 996. Ses maux sont donc $\pi \alpha \tau p \hat{\varphi} \alpha$ к $\alpha \grave{\imath} \mu \eta \tau \rho \hat{\varphi} \alpha$, cf. 1194; Esch., Choéph., 269 sq.

85 DE SCHUTTER, art. cit., p. 107-108.

86 EUR., Héracl., 873-878.

87 DE SCHUTTER, art. cit., p. 122. 
Examinons donc quel sort réservait l'eschatologie au parricide. On sait que les Érinyes, filles effrayantes de la Nuit, incarnent les esprits de la vengeance en cas de parricide : ces anciennes puissances démoniaques, qui poursuivent l'assassin d'un parent, symbolisent en quelque sorte la mauvaise conscience du meurtrier. Elles entrent en action dès que le sang a été versé et, par leur intervention, le crime trouve son châtiment sur terre. Originellement, vu que la notion de rétribution ou de punition dans l'au-delà semble étrangère à Homère, il est vraisemblable que l'expiation se limitait à cela, mais dès que l'idée d'un châtiment porthume apparut, une peine précise fut réservée aux fils irrespectueux et aux parricides. Ainsi, vers le milieu du Ve siècle, il est clairement dit chez Eschyle que les Eunémides veulent emmener Oreste sous terre pour qu'il y subisse les supplices dus à son matricide : il verra là des mortels impies qui ont offensé un dieu, un hôte ou leurs parents ${ }^{88}$. Et lorsque, vers 460 , Polygnote peignit sa célèbre Nekyia sur le mur de la Leschè des Cnidiens à Delphes, il représenta sur les bords de l'Achéron un homme étranglé par son père qu'il avait maltraité icibas ${ }^{89}$. Le thème du châtiment des mauvais fils était donc devenu populaire au point de figurer dans l'art pictural du Ve siècle. À la fin de ce siècle, en 405, Aristophane, s'inspirant des conceptions orphiques pour sa description de la géographie de l'Hadès, mentionna un grand bourbier et un torrent de fange qui retiennent les parjures, ceux qui ont frappé leur père ou violé les lois de l'hospitalité ${ }^{90}$. Durant la première moitié du IVe siècle, Platon lui aussi prévit dans sa complexe

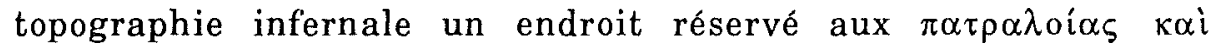
$\mu \eta \tau \rho \alpha \lambda \alpha^{\prime} \alpha \varsigma$ : ils seront précipités dans le Tartare et y resteront un an avant d'échouer dans le Pyriphlégéton, fleuve de lave, et enfin dans le marais Achérousiade ${ }^{91}$. Il ajoutera ultérieurement que les tourments qui attendent le fils impie dans l'Hadès sont pires encore que la mort elle-même $\mathrm{e}^{92}$. Plus tard, Virgile se souviendra de ces descriptions imagées ${ }^{93}$. Le thème fut même introduit dans les discours prononcés au

88 ESCH., Eum., 269-272.

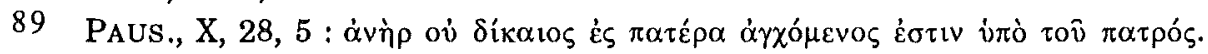
Ce fils impie est associé à un sacrilège à qui une Furie oblige d'avaler une coupe de poison, cf. A. REINACH, op. cit., p. 106 sq.

90 ARISTOPH., Gren., 149-150; 273 sq. : ils sont plongés «dans la boue», un châtiment que les orphiques réservaient à l'origine aux non-initiés, cf. E. ROHDE, Psyché, $1928^{10}$ (trad. franç.), p. 258, n. 1.

91 PLAT., Phédon, 114a; Rép., 615c (le mythe d'Er le Pamphylien).

92 Plat., Lois, 881a-b. 
tribunal : pour convaincre les juges qu'un certain Aristogiton ne méritait pas leur pardon, un orateur rappela qu'il n'obtiendrait certainement pas l'indulgence des dieux de l'Hadès et serait précipité parmi les impies, puisqu'il avait abandonné son père en prison et ne l'avait pas enseveli ${ }^{94}$.

Comme la notion de paradis n'a pas fait fortune en Grèce, du moins dans la religion officielle, la piété filiale ne donnait pas lieu à des récompenses posthumes aussi nettement définies que les punitions promises à l'impie. Toutefois, celui qui respectait ses parents en était récompensé de son vivant, et, dit Euripide, il restait cher aux dieux même après la mort ${ }^{95}$.

\section{Zeus Patrôos, le dieu protecteur du pène}

La religion et le droit s'accordaient donc pour contraindre les fils rebelles à la docilité, et le tribunal infernal que présidait Minos est le correspondant mythologique des tribunaux athéniens. En plus du jugement posthume, la colère des dieux s'abattait sur les fils irrespectueux avant même qu'ils aient quitté le monde des vivants. Si l'assassinat d'un parent éveillait le courroux des Érinyes ou la vengeance de l'âme irritée du mort - qui devenait un fantôme redoutable, $\pi \rho \circ \sigma \tau \rho{ }^{\prime} \pi \alpha \operatorname{loc}^{96}$-, c'est Zeus en personne qui intervenait pour secourir un père maltraité. Je me permets de reprendre ici, afin de les approfondir, les conclusions auxquelles m'avait mené mon étude sur la

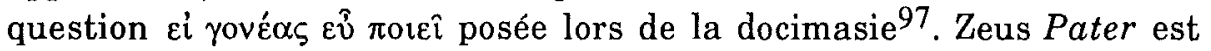
l'archétype du chef de famille patriarcale. La position et la conduite du Zeus homérique, père des dieux et des hommes, sont modelées sur celles

93 VIRG., En., VI, 609. Il est intéressant de noter à titre indicatif que l'Enfer dans la mythologie chinoise est divisé en dix-huit secteurs répartis entre dix tribunaux que président les Rois-Yama, Yen-Wang (dérivé du sanskrit Yama, dieu des morts, qui par ailleurs porte en Inde le titre de Pitripatri, "Seigneur des Pères») : le huitième tribunal est réservé à ceux qui ont manqué à la piété filiale. Ils y sont broyés, plongés dans la fosse des latrines, dépecés, etc. Cf. $N$. VANDIER-NICOLAS, Le jugement des morts en Chine, in Le jugement des morts, Sources orientales, 1961, p. 244; H. MASPERO, Le taoisme et les religions chinoises, 1971, p. 202.

94 Ps. DÉM., XXV, 53 (il avait aussi maltraité sa mère et sa sœur).

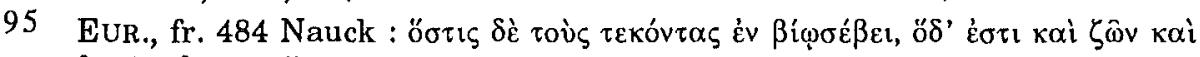

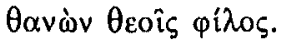

96 ANTIPHON, IIIe Tétr., I, 4; II, 8; IV, 10; E. RoHDE, op. cit., p. 217, n. 2; G. GLotZ, La solidarité..., p. 61 sq.

97 DE SCHUTTER, art. cit., p. 120-122. 
du père humain de la société archaïque ${ }^{98}$ et, du point de vue linguistique, la racine ${ }^{*}$ pater est la «qualification permanente du dieu suprême des Indo-Européens» ${ }^{99}$. Bref, Zeus Pater, garant d'ordre et de justice, est la contrepartie céleste de l'autorité paternelle du chef de famille. Ceci nous rappelle que la virtualité symbolique de la figure du père est due, selon l'expression de P. Ricœur, à «son potentiel de transcendance» ${ }^{100}$ : depuis Freud, on sait que le père est moins le géniteur que le donneur de loi et la source d'institution. En termes d'analyse freudienne, le père apparaît comme «la personnification de toute contrainte sociale impatiemment supportée» 101 , il est le symbole de l'autorité traditionnelle qui brime les efforts d'émancipation. Pour devenir homme et acquérir lui-même l'autorité paternelle, le fils devra se mesurer à cette autorité inhibante et castratrice. E. Dodds a raison de voir dans l'horreur particulière avec laquelle les Grecs ont considéré les offenses contre un père un indice de "refoulements puissants» et dans le mythe de la castration d'Ouranos "un reflet des désirs humains inconscients» ${ }^{102}$. L'irrespect du père, la révolte contre son autorité, sont donc soumis au mécanisme psychique du complexe œdipien, mais ce qui nous intéresse ici, c'est de voir comment les Grecs ont vécu et géré cette constante de l'inconscient.

Pour Hésiode déjà, "le crime est pareil de qui maltraite un suppliant

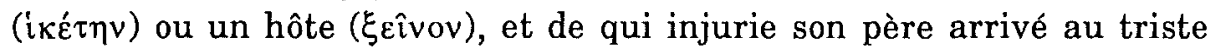
seuil de la vieillesse en lui adressant des paroles malveillantes : contre celui-là, c'est Zeus lui-même qui s'irrite et lui inflige un dur châtiment pour ses actes criminels» 103 . Le poète se réfêre manifestement, pour les

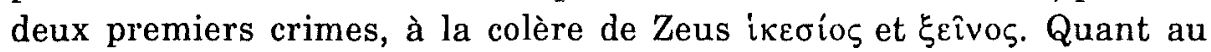

98 M. CALHOUN, Zeus the Father in Homer, in TAPhA, 66 (1935), p. 1-17.

99 É. BENVENISTE, op. cit., p. 210.

100 P. Riccur, De l'interprétation. Essai sur Freud, 1966, p. 520. Sur la symbolique de la transcendance du père et du ciel, cf. M. EliADE, Traité d'histoire des religions, $1964^{2}$, chap. II.

101 S. FReud, Introduction à la psychanalyse, 1979 (trad. franç.), p. 190. Pour FREUD, le dieu personnel n'est autre psychologiquement qu'un père transfiguré : Dieu tout-puissant et juste est une sublimation grandiose du père, cf. Totem et tabou, 1965 (trad. franc.) : le complexe d'Edipe est à la base de toute religion. Pour une approche sociopsychanalytique de la question, $\mathrm{cf}$. G. MendeL, La révolte contre le père, 1968.

102 E. DoDDs, op. cit., p. 55; 68, n. 103 : plusieurs exemples empruntés à la mythologie de père bannissant leur fils. Cf. aussi Platon, Lois, 931b-c; W. BuRKERT, Homo Necans, 1983 (trad. angl.), p. 72 sq.

103 Hés., Trav., 327-334. 
troisième méfait, c'est l'intervention de Zeus $\pi \alpha \tau \rho \hat{\emptyset} \circ \varsigma$ qu'il suscite. Hésiode ne le dit pas explicitement, mais nous allons voir que les Athéniens du Ve siècle faisaient de Zeus Patrôos le garant du respect que les parents étaient en droit d'attendre de leurs enfants. Nous avons constaté que ceux qui violaient les lois de la piété filiale et celles de l'hospitalité subissaient un sort commun dans l'Hadès. Eschyle lui

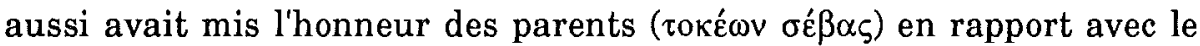
respect des hôtes $(\xi \varepsilon v o \tau i ́ \text { ov })^{104}$ placés sous la protection de Zeus Xenios. Or, pour Homère déjà, le $\xi_{\varepsilon} \hat{\imath} v o \varsigma \pi \alpha \tau \rho \hat{\text { ạo }}{ }^{105}$ venu chercher refuge auprès

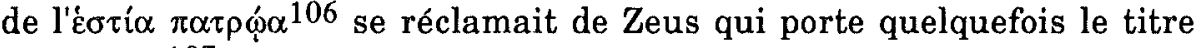

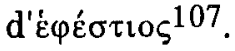

Dans un passage particulièrement significatf de son Alceste, Euripide débat sur les devoirs respectifs des parents et des enfants : Admète renie son père Phérès qui n'avait pas accepté de mourir à sa place. Il lui conseille hautainement de procréer sans perdre de temps

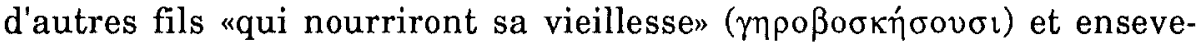
liront son cadavre car il refuse désormais de lui rendre les derniers devoirs et de lui servir de instamment son toit et répudie le foyer paternel, $\pi \alpha \tau \rho \varphi \alpha^{\prime} \alpha \dot{\varepsilon} \sigma \tau i \alpha v$ (v. 734740). Ceci nous permet déjà de mieux comprendre l'épithète Patrôos de Zeus dans ce contexte de traditions familiales héritées des ancêtres. Mais poussons l'étude plus loin.

Le malheureux Strepsiade est accablé par les dettes de son fils Phidippide, il l'a donc envoyé suivre les cours de Socrate pour qu'il apprenne à évincer ses créanciers et devienne "le libérateur des maux paternels", $\pi \alpha \tau \rho \varphi \varphi \omega v \kappa \alpha \kappa \hat{\omega} v^{108}$. Mais lorsque Phidippide revient de l'école et met en pratique les leçons de sophistique de son maître, il établit une loi nouvelle au terme de laquelle les fils pourront battre leur père (v. 1420-1424). Et de fait, il rosse son père et lui prouve qu'il a raison d'agir ainsi. Strepsiade lui enjoint alors de vénérer Zeus Patrôos :

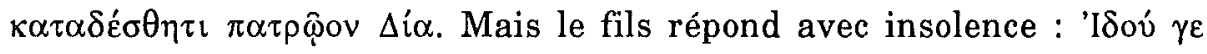

104 Esch., Eum., 544-549.

105 Il., VI, 215; Od., I, 187, II, 254, 286; XVII, 69, 522; EUR., Héc., 19; $26 ; 82$.

106 Od., XVII, 80; XX, 336; XXI, 61; PIND., Pyth., XI, 14; SoPH., Ajax, 860-861; El., 881; Eur., Héc., 22; Méd., 680-682; XÉN., Cyr., I, 6, 1 : Cyrus associe Zeus Patrôos à Hestia Patrôa dans une prière; VII, 5, 57; VIII, 7, 3. Par interpretatio graeca, XÉNOPHON identifie Zeus à Ormuzd et Hestia au feu divin des Perses.

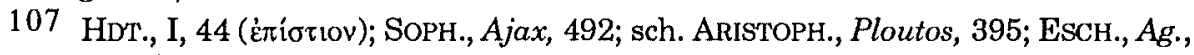

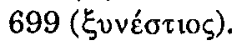

108 ARISTOPH., Nuées, 1162; cf. supra, p. 8. 


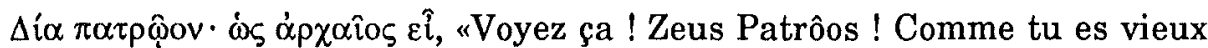
jeu !» 109

Oreste, quant à lui, agit à l'inverse : il revient d'exil pour venger le

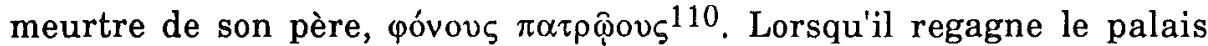
paternel, $\pi \alpha \tau \rho \hat{\varphi}$ ov oî́co ${ }^{111}$, et la terre ancestrale, $\gamma \alpha i \alpha \varsigma \pi \alpha \tau \rho \varphi^{\prime} \alpha \varsigma^{112}$, il invoque Zeus Patrôos et Tropaios. Déjà Électre, fidèle à son père, se lamentait $\varepsilon \dot{v} \theta \alpha \lambda \alpha \dot{\alpha} \mu \circ \varsigma \pi \alpha \tau \rho \varphi_{0} \varsigma_{\varsigma}{ }^{113}$ en priant Zeus de venger le meurtre

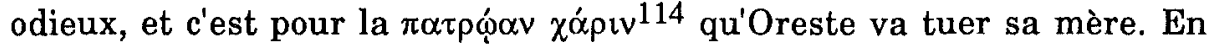
agissant ainsi, il fournit l'exemple de la piété filiale parfaite car ne pas venger son père, c'est être impie ${ }^{115}$. La vengeance du père assassiné allait de soi, au point que l'expression «insensé qui tue le père et laisse vivre les enfants" était devenue proverbiale ${ }^{116}$. Le geste d'Oreste est justifié parce que "c'est de Zeus que vient l'oracle qui lui a commandé de venger le meurtre de son père" 117 , et "c'est du meurtre du père que Zeus fait le plus de cas»118. Oreste obéit donc à une instance divine lorsqu'après avoir hésité entre venger son père et laisser vivre sa mère, il se décide à prendre cause pour le fondateur de la famille ${ }^{119}$ : il n'a

109 ARISTOPH., Nuées, 1468-1469; 821 sq.

110 SoPH., $E l ., 778-779 ; 955$.

111 EUR., El., 611; 810; 1005; cf. aussi HÉs., Trav., 376-378.

112 EsCH., Eum., 755 sq.; Eur., Iph. Taur., 50-51; 135; 188 : Oreste est le pilier du

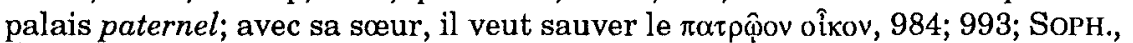

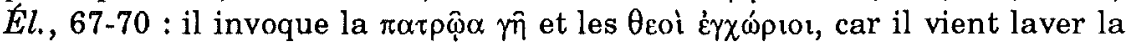
souillure du $\pi \alpha \tau \rho \hat{\varphi}$ ov $\delta \hat{\omega} \mu \alpha ; 978$. En tant que Tantalide (cf. infra, n. 132),

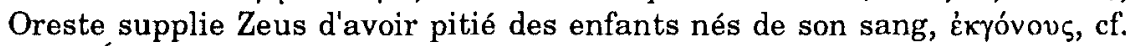
Eur., El., 671; Or., 1241; Esch., Choéph., 18-20; 246 sq. Le devoir de vendetta qui oblige à poursuivre le meurtrier d'un parent, et particulièrement du père, a souvent été considéré comme un élément du culte des morts, cf. E. RoHDE, op. cit., p. 213 sq.; G. GLoTz, op. cit., p. 59 sq.

113 Eur., El., 132-139.

114 EUR., Or., 828-830.

115 EUR., El., 974-976; PLUT., Is. et Os., XIX, 358c.

116 ARISTOTE, Rhét., I, 15; II, 21; HDT., I, 155; Eur., Andr., 519-522; déjà Od., III, 196-197. L'expression est attribuée au poète STASIMOS DE CHYPRE.

117 Esch., Eum., 622-624; Choéph., 382-385 : la colère de Zeus s'abat sur les parents meurtriers.

118 EsCH., Eum., 640-642. Les Érinyes aussi sont provoquées par le sang d'un père,

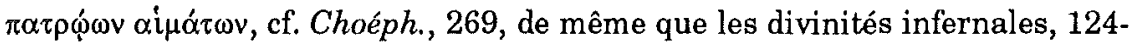
128.

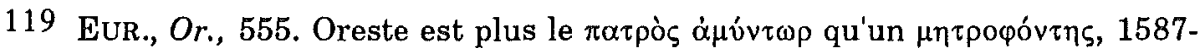
1588. Une fois la vengeance accomplie, il préférerait détruire le $\pi \alpha \tau \rho \hat{\varphi}$ ov $\delta \hat{\omega} \mu \alpha$ plutôt que de le laisser à Ménélas, 1595. 
fait que se plier au devoir de la vengeance du sang qu'imposait l'antique justice familiale, la $\theta \varepsilon ́ \mu \iota \varsigma$, "émanation céleste envoyée par Zeus» 120 .

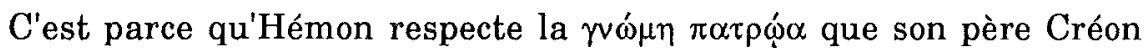
est satisfait de lui, mais Antigone est tout le contraire d'un enfant respectueux : elle aura beau implorer Zeus Protecteur de la famille, sía $\xi$ v́vaıนov, elle n'obtiendra pas gain de cause ${ }^{121}$. Pour Platon, le citoyen témoin de l'impiété d'un patraloias doit chasser l'assaillant et, s'il y manque, il encourra lui-même, ainsi que le malfaiteur, la malédiction de Zeus Homognios et Patrôos ${ }^{122}$. Ces deux adjectifs se trouvent encore associés lorsque, au nom de Zeus Homognios, Hermione conjure Oreste de l'aider à fuir la colère de son mari et de la ramener au $\pi \alpha \tau \rho \hat{\varphi} o v$

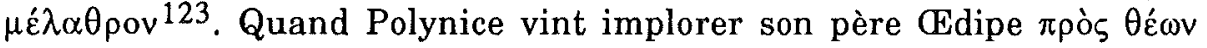

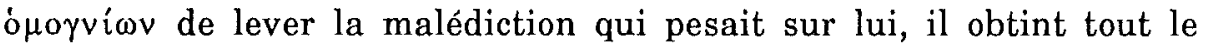
contraire : Edipe répéta l'imprécation qu'il avait jadis lancée contre

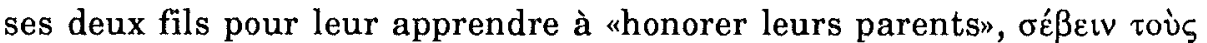
$\varphi v \tau \varepsilon v \sigma \sigma \alpha v \tau \alpha \varsigma^{124}$. Il n'est pas fortuit que, chez Eschyle, cette imprécation soit dite $\dot{\alpha} \rho \grave{\alpha} v \pi \alpha \tau \rho \omega_{\alpha} \alpha{ }^{125}$. La dépouille de Polynice sera jetée hors des murailles de la ville, sans sépulture, car "même mort, il gardera sa souillure à l'égard des dieux ancestraux, $\theta \varepsilon \hat{\omega} v \pi \alpha \tau \rho \varphi \omega \omega v » 126$. Par contre, Étéocle sera honoré de pieuses funérailles car «il est pur à l'égard des

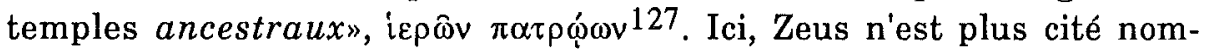
mément, mais il semble clair que c'est lui qui se dissimule derrière cet ensemble non défini de dieux ancestraux invoqués lorsque l'ordre

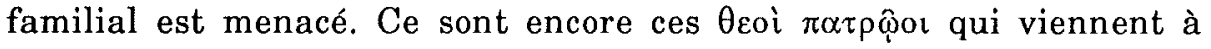

120 G. GLOTZ, op. cit., p. 21 et n. 4.

121 SopH., Ant., 639 sq.; 658-659.

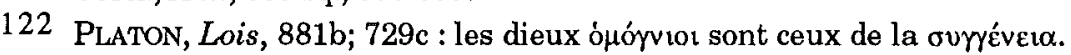

123 Eur., Andr., 921-923. La scholie d'ARISTOPH., Nuées, 1468 rapproche aussi les

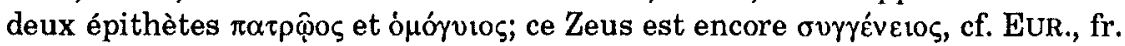

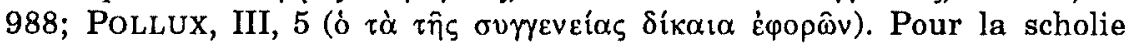

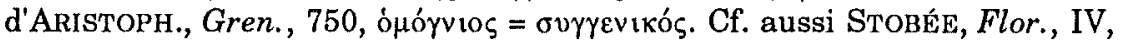
$24,15$.

124 SOPH., Ed. Col, 1333, 1377.

125 Esch., Sept., 944-946.

126 EsCH., Sept., 1017-1018 : SoPHOCLE s'est manifestement souvenu d'EsCHYLE dans Ant., 194; 210 : Polynice sera privé de funérailles car il n'est revenu au pays que pour livrer aux flammes "la terre ancestrale et les dieux familiaux",

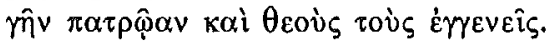

127 Esch., Sept, 1010. Cf. aussi Eur., Phén., 604-605 : Polynice, banni, s'adresse aux autels ancestraux. 
l'esprit d'Électre au moment où elle apprend que sa mère a eu un songe funeste annonçant le retour d'Oreste, c'est-à-dire une vengeance imminente ${ }^{128}$. Par ailleurs, en énumérant les cultes que doit rendre l'homme pieux, Platon cite, après les $\theta$ coì $\pi \alpha \tau p \hat{o}$ ol, les honneurs "que les parents obtiennent de leur vivant» 129 . Usant d'une formule plus romaine que grecque, il va jusqu'à identifier les parents vivants et les ancêtres avec les dieux familiaux ${ }^{130}$.

Dans un discours d'Isée, le fils que Ménéklès avait adopté pour être le soutien de sa vieillesse reproche à son oncle, qui l'attaque en justice, de s'efforcer de priver son frère de descendance "sans respecter les

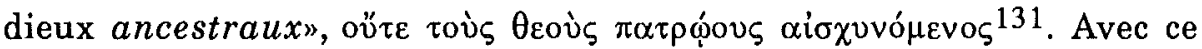
dernier exemple, nous avons quitté le monde imaginaire de la tragédie et de la législation de Platon pour nous tourner vers la réalité d'un procès : même si aucun document épigraphique ne mentionne Zeus Patrôos en Attique ${ }^{132}$, on voit bien que ce dieu a joué un rôle appréciable en tant que protecteur des pères dans la pensée des Athéniens de l'époque classique. Pour en terminer sur ce point, laissons la parole à Arrien : ov̉

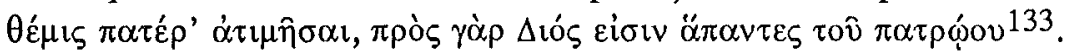

\section{La piété filiale à la base du culte des morts}

J'ai limité cette étude aux devoirs des enfants envers leurs parents vivants, et plus spécialement du fils envers son père, mais même la mort du père ne libère pas encore le fils de ses devoirs. Bien au contraire, le respect qu'il devait à son vieux père se prolonge dans les

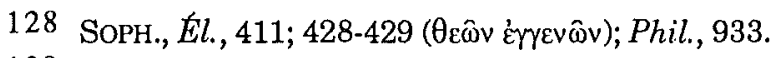

129 Platon, Lois, IV, 717b; 930e. Il est vrai qu'ici, c'est Némésis, messagère de Dikè, et non Zeus (comme en $881 \mathrm{~b}$ ), qui poursuit celui qui ne respecte pas ses parents en paroles. Ailleurs, c'est Dikè elle-même qui est la vengeresse du sang

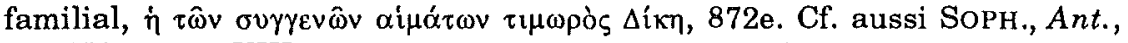
451; XÉN., Cyr., VIII, 7, 17 : ce sont encore ces mêmes théoi patrôoi que le vieuX Cyrus invoque sur son lit de mort en exhortant ses enfants à s'entendre après son départ; supra, n. 35.

130 PLATON, Lois, V, 740b.

131 IsÉE, II, 1.

132 De SchuTTER, art. cit., p. 121, n. 105. J'y ai expliqué pourquoi Platon (Euth., 302c-d) écrit que les Athéniens n'ont pas de Zeus Patrôos : il veut dire par là que le dieu n'a pas de culte institué à Athènes, contrairement à Apollon Patrôos honoré au sein des phratries. Toutefois, Zeus Patrôos est pour la lignée mythique des Tantalides et celle des Héraclides l'équivalent d'Apollon pour les phratères d'Attique : l'ancêtre mythique, cf. supra, n. 112.

133 ARRIEN, Ep., III, 11, 5. 
honneurs funèbres dûs à sa dépouille : ce sont les funérailles, à la fois "derniers devoirs" et premier acquittement d'une série de soins pieux grâce auxquels les relations entre le défunt et ses survivants ne sont pas interrompues. Je n'insisterai pas ici sur le rituel funèbre, mais il me semble opportun de souligner que la piété filiale est à la base du culte des morts. Le respect et l'entretien du père en constituent le premier acte, les funérailles le second, et les rites posthumes le corps principal. Ménéklès, par exemple, adopta un fils afin d'avoir quelqu'un qui

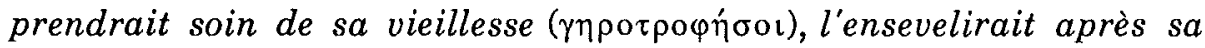
mort et lui rendrait ensuite les devoirs prescrits par la coutume ( $\tau \grave{\alpha}$ $\left.v^{\circ} \mu_{\imath} \zeta{ }_{o} \mu \varepsilon v \alpha\right)^{134}$. L'orateur précise à plusieurs reprises que la pension alimentaire et les honneurs funèbres sont les deux facettes d'un même

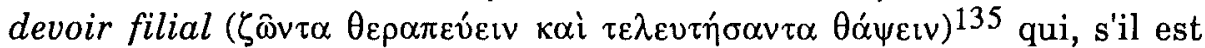

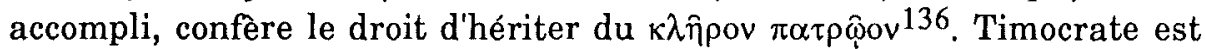

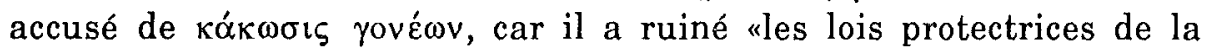
vieillesse qui obligent les enfants à nourrir leurs parents encore en vie et à leur rendre les derniers devoirs lorsqu'ils meurent» ${ }^{137}$. Nous avons vu que la bonne conduite du citoyen envers ses parents était requise lors de la docimasie; or, les bouleutes lui demandaient également s'il possédait des tombeaux familiaux et où se trouvaient ces

134 IsÉE, II, 10; VII, 30; IX, 7; Astyphilos fit de même afin de permettre à son fils de

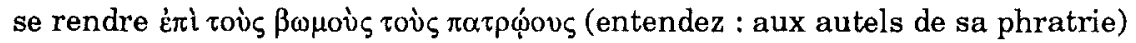

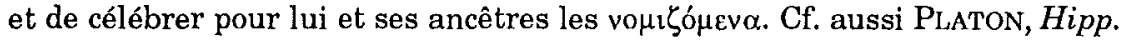
maj., 291d-e.

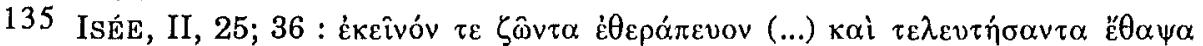

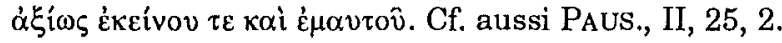

136 IséE, II, 45;VIII, 21; 25; 38-39. Il est malhonnête de réclamer la succession après avoir négligé les derniers devoirs, comme le fait impudemment un certain Chariadès, IV, 19.

137 Dém., C. Tim., 107; cf. aussi LYC., C. Léocr., 147; LYs., XIII, 45 : c'est un spectacle affligeant que de voir abandonnés des parents âgés «qui attendaient

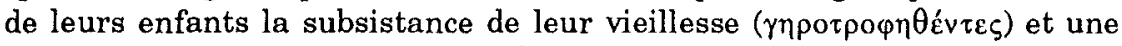
sépulture après leur mort ( $\tau \alpha \varphi \eta ́ \sigma \varepsilon \sigma \theta \alpha \imath)$ ); EUR., Suppl., 918-924. La définition de la piété filiale que fournit Confucius correspond exactement à notre propos : «Selon les rites, les parents seront servis de leur vivant; selon les rites, ils seront enterrés; selon les rites seront faits les sacrifices à leurs mânes», cf. Entretiens, II, 5; I, 9. De même, selon le Corpus canonique de Ceylan, les cinq façons pour un enfant de rendre hommage à ses parents sont les suivantes : «ayant été soigné par eux, je prendrai soin d'eux, j'accomplirai mes devoirs envers eux, je conserverai la tradition familiale, j'agirai de façon à protéger ses biens, j'offrirai des aumônes pour mes parents défunts", cf. W. RAHULA, op. cit., p. 131. 


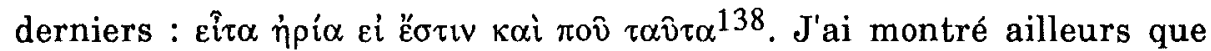
le but de la question était de s'assurer que le candidat n'était pas un nouveau venu sur le sol attique, mais qu'il en tirait les origines de sa lignée ou, du moins, qu'il y était établi depuis trois générations ${ }^{139}$. Il apparaît à présent que la question visait aussi à vérifier s'il avait bel et bien accompli les devoirs imposés par la piété filiale au cas où ses parents seraient déjà décédés. En effet, dans son discours sur la docimasie de Philon, Lysias lui reproche sa mauvaise conduite envers sa mère. Celle-ci n'osa même pas lui confier le soin de sa sépulture, car «elle le savait capable de ne pas lui rendre les derniers devoirs» : une telle indignité devrait suffire, dit l'orateur, à justifier son exclusion lors de la docimasie $(\dot{\alpha} \pi \circ \delta \circ \kappa \iota \mu \alpha \sigma \theta \hat{\eta} \vee \alpha \iota)^{140}$. Xénophon confirme cette explication lorsqu'il dit : «si un citoyen ne prend pas soin des tombeaux de ses parents morts, cela aussi l'État le recherche lors de la docimasie des archontes» 141.

C'est à la tragédie que j'emprunterai un dernier exemple de ce double aspect de la piété filiale : en tuant de sa main ses propres enfants pour accomplir sa terrible vengeance, Médée se prive elle-même des descendants qui lui auraient assuré «ce qu'envient les hommes», la géroboskia et de dignes funérailles ${ }^{142}$.

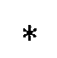

Notre enquête nous a mis en présence de fils irrespectueux et impies: ils insultent leurs parents ou vont jusqu'à les battre, ils refusent de les assister durant leur vieillesse et négligent leurs funérailles. Ces conflits de générations ont existé de tout temps et peuvent s'expliquer partiellement par les lois de la psyché humaine, mais il semble bien qu'ils avaient atteint dans la société athénienne de la fin du Ve siècle et du IVe siècle un maximum d'intensité. Les

138 ARISTOTE, Const. Ath., LV, 2-3; DÉM., C. Eub., 66-67. Les mêmes questions sont posées pour établir la successibilité d'un parent, cf. ISÉE, VI, 51; 64-65: nôे

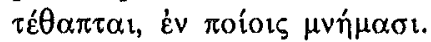

139 De SCHUTTER, art. cit., p. 120.

140 Lys., XXXI, 20-21.

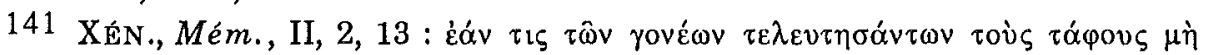

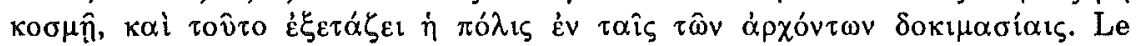
terme коб $\mu \hat{n}$ semble indiquer que XÉNOPHON ne pense pas seulement auX funérailles, mais aussi au culte posthume qui consiste à revenir à dates fixes au cimetière pour orner la sépulture et faire des libations.

142 Eur.., Méd., 1031-1035. 
témoignages des Tragiques et d'Aristophane, qui accordent tant d'importance à Zeus en sa qualité de protecteur des pères et qui dépeignent une société de fils impies, ne relèvent pas entièrement de la fiction poétique : tragédie et comédie reflètent, à leur façon, une réalité sociale et psychologique, et une remise en question de certaines valeurs traditionnelles ${ }^{143}$. Les exemples empruntés aux plaidoyers attiques ou tirés de droit prouvent que les situations théâtrales correspondent à des réalités vécues et juridiquement définies ${ }^{144}$.

La piété filiale prend la forme que lui imposent les traditions sociales et religieuses. Dans une société en mutation, où la stabilité des structures familiales s'effondre et où la puissance du paterfamilias ne parvient plus à se justifier, cette piété filiale peut aisément se muer en impiété.

Rue de l'Église, 18

Xavier DE SCHUTTER

B - 1630 LINKEBEEK

143 J.-P. VERNANT, Mythe et tragédie en Grèce ancienne, 1986, p. 15 : "La matière véritable de la tragédie, c'est la pensée sociale propre à la cité, spécialement la pensée juridique en plein travail d'élaboration». Mais la tragédie ne reflète pas exactement la réalité sociale : «elle la met en question" (p. 25) en opposant les anciennes légendes héroïques qui constituent pour la cité son passé, et les formes nouvelles de pensée juridique et politique.

144 Ceci pour répondre à la remarque prudente de Roussel, art. cit., p. 219, n. 2, à propos de la valeur du témoignage de la comédie. 